\title{
Clinical Significance of Cerebral Oxygenation During Exercise in Patients With Coronary Artery Disease
}

\author{
Akira Koike, MD*; Osamu Nagayama, BS*; Masayo Hoshimoto-Iwamoto, PhD*,**; \\ Takeya Suzuki, $\mathrm{MD}^{\dagger}$; Akihiko Tajima, BS*; \\ Tokuhisa Uejima, MD*; Tadanori Aizawa, MD*
}

\begin{abstract}
Background Recent investigations have demonstrated that cerebral oxyhemoglobin $\left(\mathrm{O}_{2} \mathrm{Hb}\right)$ decreases during exercise in patients with left ventricular dysfunction, reflecting a cerebral hypoxia. We sought to establish a prognostic value of decreased cerebral $\mathrm{O}_{2} \mathrm{Hb}$ during exercise in cardiac patients, and to compare it with those of indexes obtained from cardiopulmonary exercise testing (CPX).

Methods and Results A total of 344 consecutive patients with coronary artery disease were enrolled in the study. All the patients performed $\mathrm{CPX}$, during which cerebral $\mathrm{O}_{2} \mathrm{Hb}$ was continuously monitored using nearinfrared spectroscopy. There were 13 cardiac deaths and 78 cardiovascular events during the prospective follow-up period of $1,231 \pm 538$ days. The change of $\mathrm{O}_{2} \mathrm{Hb}$ measured at the forehead from rest to peak exercise $\left(\Delta \mathrm{O}_{2} \mathrm{Hb}\right)$ was significantly lower in non-survivors than in survivors $(-1.5 \pm 3.3$ vs $1.7 \pm 3.2 \mu \mathrm{mol} / \mathrm{L}, \mathrm{p}=0.0004)$. By multivariate Cox proportional hazards analysis, $\Delta \mathrm{O}_{2} \mathrm{Hb}$ and left ventricular ejection fraction (LVEF) were found to be independent prognostic markers for cardiac deaths. The $\Delta \mathrm{O}_{2} \mathrm{Hb}$, LVEF and peak oxygen uptake were found to be significant prognostic markers for cardiovascular events, mainly for heart failure worsening and sudden cardiac death. Conclusion The present findings suggest that a decrease in cerebral $\mathrm{O}_{2} \mathrm{Hb}$ during exercise predicts future cardiovascular events in patients with coronary artery disease. (Circ J 2008; 72: 1852-1858)
\end{abstract}

Key Words: Brain; Cerebral oxygenation; Exercise

I $\mathrm{n}$ resting conditions, complex compensatory mechanisms are believed to adequately regulate blood flow to vital organs, especially to the brain. During exercise, however, the $\mathrm{O}_{2}$ demand of exercising muscles surges to levels 10-15 times higher than that in the resting condition. The blood flow to the exercising muscles increases tremendously to meet this sudden surge in $\mathrm{O}_{2}$ demand, thereby leading to a relative hypoperfusion of other organs. Our group recently studied cerebral oxygenation during exercise using near-infrared spectroscopy (NIRS) in patients with left ventricular dysfunction! We found, as a result, that nearly half of the patients exhibited decreases in the cerebral oxyhemoglobin $\left(\mathrm{O}_{2} \mathrm{Hb}\right)$ during exercise, and that the decrease was more prominent in patients with a lower left ventricular ejection fraction (LVEF)! In these patients, cerebral $\mathrm{O}_{2} \mathrm{Hb}$, a parameter that initially remained constant at lower work rates during incremental exercise, began to decrease at higher work rates 1,2 The decrease in cerebral $\mathrm{O}_{2} \mathrm{Hb}$ presumably reflected a cerebral hypoxia during exercise resulting from impaired $\mathrm{O}_{2}$ transport to the brain.

While risk stratification of chronic heart disease had been primarily based on resting hemodynamic measurements,

(Received April 15, 2008; revised manuscript received June 29, 2008; accepted July 3, 2008; released online October 3, 2008)

*The Cardiovascular Institute, Tokyo, **School of Health and Sports Science, Juntendo University, Chiba and Department of Cardiovascular Medicine, Toho University Omori Medical Center, Tokyo, Japan

Mailing address: Akira Koike, MD, The Cardiovascular Institute, 7-310 Roppongi, Minato-ku, Tokyo 106-0032, Japan. E-mail: koike@ cvi.or.jp

All rights are reserved to the Japanese Circulation Society. For permissions, please e-mail: cj@j-circ.or.jp cardiopulmonary exercise testing (CPX) has now become indispensable in singling out those patients with a poor prognosis. Among the parameters obtained from CPX, the peak $\mathrm{O}_{2}$ uptake $\left(\dot{\mathrm{V}}_{2}\right)$ is considered a gold standard for identifying patients with a poor prognosis and selecting candidates for cardiac transplantation? The ratio of the increase in ventilation ( $\dot{\mathrm{VE}})$ to the increase in $\mathrm{CO}_{2}$ output $(\dot{\mathrm{V} C O} 2)$ during exercise ( $\mathrm{VE} / \dot{\mathrm{V} C O} 2$ slope) and the ratio of the increase in $\dot{\mathrm{V}} \mathrm{O}_{2}$ to the increase in work rate $\left(\Delta \dot{\mathrm{V}} \mathrm{O}_{2} / \Delta \mathrm{WR}\right)$ are also independent prognostic markers in cardiac patients.

In 1999, Lee et al reported that cerebral metabolism measured by magnetic resonance spectroscopy is abnormally deranged in patients with heart failure? They also found that this abnormality is an independent predictor of mortality in these patients? The cerebral metabolic abnormality is assumed to be due to overall and/or local disturbances of cerebral blood flow, that is, impaired cerebral oxygenation? The impaired cerebral oxygenation can be detected by the non-invasive measurement of cerebral $\mathrm{O}_{2} \mathrm{Hb}$ using NIRS, and the detection might be more sensitive during exercise in which the $\mathrm{O}_{2}$ demand by exercising muscles increases tremendously, rather than measurements taken at rest. If the cerebral metabolic abnormality resulting from decreased cerebral $\mathrm{O}_{2}$ transport is related to prognosis, the decrease in cerebral $\mathrm{O}_{2} \mathrm{Hb}$ during exercise must also influence the prognosis.

In the present study, we sought to establish a prognostic value of decreased cerebral $\mathrm{O}_{2} \mathrm{Hb}$ during exercise in cardiac patients. We selected patients with coronary artery disease, and compared the prognostic power of cerebral $\mathrm{O}_{2} \mathrm{Hb}$ during exercise with those of established respiratory gas indexes obtained from CPX, as cerebral oxygenation depends on cardiopulmonary function during exercise,, 7 


\section{Methods}

\section{Study Patients}

We prospectively evaluated 344 consecutive patients with stable coronary artery disease $(65.0 \pm 9.4$ years). These patients performed CPX at the Cardiovascular Institute between February 2001 and August 2003. Coronary artery disease had been diagnosed by the presence of significant coronary stenosis defined as a $\geq 75 \%$ reduction in the luminal diameter of coronary vessels or the presence of myocardial infarction diagnosed according to the World Health Organization criteria8. Among these patients, 201 had previous myocardial infarction. Critical coronary stenosis considered inappropriate for performing CPX had been treated by percutaneous coronary intervention and/or coronary artery bypass graft surgery prior to CPX according to current therapeutic guidelines. Patients with orthopedic difficulty in pedaling a cycle ergometer and those with cerebrovascular disease diagnosed based on clinical documentation were excluded from the study. The protocol was approved by the Human Subjects Committee of the Cardiovascular Institute. Its purposes and risks were explained to each patient, and informed consent was obtained from all of them.

\section{Follow-up}

After the CPX, patients were prospectively followed up at the outpatient clinic of the Cardiovascular Institute. The primary endpoint was defined as cardiac death. Causes of cardiac death were categorized into acute myocardial infarction, progressive heart failure and sudden cardiac death. Sudden cardiac death was diagnosed according to published criteria? The secondary endpoint was defined as a composite of a worsening of angina pectoris requiring hospitalization, new acute myocardial infarction, a worsening of heart failure requiring hospitalization and cardiac death: only the first event in each patient was included in this analysis.

\section{Exercise Testing}

An incremental symptom-limited exercise test was performed using an upright, electromagnetically braked cycle ergometer (Corival 400, Lode, Holland). Exercise began with a 4 -min warm-up at $0 \mathrm{~W}$ or $20 \mathrm{~W}$ at $60 \mathrm{rpm}$, with the load then being increased incrementally by $1 \mathrm{~W}$ every $6 \mathrm{~s}$ (10 W/min). The electrocardiogram was monitored continuously during the exercise tests using a System ML-6500 (Fukuda Denshi Co Ltd, Tokyo, Japan). Cuff blood pressure was measured at rest on the cycle ergometer and then every minute during exercise testing with an automatic indirect manometer (STBP-780; Nippon Colin Co Ltd, Aichi, Japan). Through a rubber mask attached to the subject's face, breath-by-breath $\dot{\mathrm{VO}}_{2}, \dot{\mathrm{V}} \mathrm{CO}_{2}$ and $\dot{\mathrm{VE}}$ were measured during the test using an AE-300S Respiromonitor (Minato Medical Science, Osaka, Japan), as previously described 10

\section{Respiratory Gas Analysis}

Prior to the calculation of the parameters from respiratory gas analyses, a 5-point moving average of the breath-bybreath data was performed. The peak $\dot{\mathrm{VO}}_{2}$ was defined as the average values obtained during the last $15 \mathrm{~s}$ of incremental exercise. The $\dot{\mathrm{VE}} / \dot{\mathrm{V}} \mathrm{CO}_{2}$ slope was calculated from the start of incremental exercise to the respiratory compensation point by a least-squares linear regression. The respiratory compensation point was determined through the following criteria: (1) the ratio of $\dot{\mathrm{V} E}$ to $\dot{\mathrm{V} C O} 2$ starts to increase after a period of decrease or stasis; and (2) the $\mathrm{PETCO}_{2}$ starts to decrease after a period of stasis. When the respiratory compensation point could not be clearly identified, the $\dot{\mathrm{VE}} / \dot{\mathrm{VCO}}_{2}$ slope was calculated from the data recorded between the start of incremental exercise and the end of the exercise. The ratio of the increase in $\mathrm{V}_{2}$ to the increase in work rate $(\Delta \dot{\mathrm{VO}} 2 / \Delta \mathrm{WR})$ was calculated by a least-squares linear regression from the data recorded between $30 \mathrm{~s}$ after the start of incremental exercise and $30 \mathrm{~s}$ before the end of exercise 4

\section{NIRS Monitoring}

Cerebral oxygenation was monitored using a commercially available NIRS system (NIRO-300; Hamamatsu Photonics KK, Hamamatsu, Japan). A probe holder containing both an emission probe and detection probe was attached to the left side of the forehead with a distance of $5 \mathrm{~cm}$ between the probes. The methodology of this system has been described in detail in previous reports ${ }^{1-15}$ NIRS attached to the forehead measures the concentration changes of $\mathrm{O}_{2} \mathrm{Hb}$ at a depth of approximately $1 \mathrm{~cm}$ from the brain surface using a modified Beer-Lambert law! ${ }^{12,13,15}$ It expresses the magnitude of the change in $\mathrm{O}_{2} \mathrm{Hb}$ as an absolute unit ( $\left.\mu \mathrm{mol} / \mathrm{L}\right)$ by incorporating an optical pathlength, assuming that the initial value is " 0 ". For the brain, this pathlength is $30 \mathrm{~cm}$ when the distance between the emission probe and detection probe is set at $5 \mathrm{~cm} \cdot 11,16 \mathrm{O}_{2} \mathrm{Hb}$ was measured every $2 \mathrm{~s}$ from $4 \mathrm{~min}$ before the start of exercise until the end of exercise. $\mathrm{O}_{2} \mathrm{Hb}$ at rest was determined as the average of the value obtained as the subjects sat on the ergometer over a 4-min period before the start of the exercise test. $\mathrm{O}_{2} \mathrm{Hb}$ at peak exercise was defined as the average value obtained during the last $30 \mathrm{~s}$ of incremental exercise, ${ }^{1,2}$ The change in $\mathrm{O}_{2} \mathrm{Hb}$ during exercise $\left(\Delta \mathrm{O}_{2} \mathrm{Hb}\right)$ was defined as the peak exercise value-the resting value.

\section{Statistical Analysis}

Data are presented as the mean $\pm \mathrm{SD}$. Intergroup differences for variables were compared using the unpaired t-test or chi-squared analysis, where appropriate. A Cox proportional hazards model was used to measure the impact of $\Delta \mathrm{O}_{2} \mathrm{Hb}$ and cardiopulmonary variables on event-free survival time. The $\Delta \mathrm{O}_{2} \mathrm{Hb}$ and cardiopulmonary variables were entered into a Cox proportional hazards model as continuous variables rather than as categorical variables. We divided the subjects into 2 groups: patients with a $\Delta \mathrm{O}_{2} \mathrm{Hb}$ during exercise of $\geq 0 \mu \mathrm{mol} / \mathrm{L}(\mathrm{n}=252)$ and those with a $\Delta \mathrm{O}_{2} \mathrm{Hb}$ during exercise of $<0 \mu \mathrm{mol} / \mathrm{L}(\mathrm{n}=92)$, and then compared the cardiovascular events between these 2 groups. We also compared the patient characteristics between survivors and non-survivors and between patients with cardiovascular events and those without events. Differences in event-free survival between the patients with a $\Delta \mathrm{O}_{2} \mathrm{Hb}$ of $\geq 0 \mu \mathrm{mol} / \mathrm{L}$ and those with a $\Delta \mathrm{O}_{2} \mathrm{Hb}$ of $<0 \mu \mathrm{mol} / \mathrm{L}$ were detected by the KaplanMeier method and compared using the logrank test. For all comparisons, $\mathrm{p}<0.05$ was considered statistically significant.

\section{Results}

During the follow-up period of 1,231 \pm 538 days, no patients underwent cardiac transplantation. By the end of the study, 13 cardiac deaths had occurred (Table 1). Of these, 7 patients died of progressive heart failure, 4 had a sudden cardiac death and 2 died of acute myocardial infarction. During the follow-up period, 78 cardiovascular events occurred (Table 1). Of these, 43 patients were hospitalized due to unstable angina, 30 were hospitalized due to a worsening of 
Table 1 Comparisons of the Cardiovascular Events Between Patients With $\Delta \mathrm{O}_{2} \mathrm{Hb} \geq 0$ and Those With $\Delta \mathrm{O}_{2} \mathrm{Hb}<0$

\begin{tabular}{lcccc}
\hline \hline & $\begin{array}{c}\text { All patients } \\
(n=344)\end{array}$ & $\begin{array}{c}\text { Patients with } \\
\Delta O_{2} H b \geq 0 \\
(n=252)\end{array}$ & $\begin{array}{c}\text { Patients with } \\
\Delta O_{2} H b<0 \\
(n=92)\end{array}$ & $p$ value \\
\hline Primary endpoint & $13(3.8)$ & $4(1.6)$ & $9(9.8)$ & 0.001 \\
Death due to worsening of heart failure & $7(2.0)$ & $3(1.2)$ & $4(4.3)$ & $N S$ \\
Sudden cardiac death & $4(1.2)$ & $0(0)$ & $4(4.3)$ & 0.005 \\
Death due to acute MI & $2(0.6)$ & $1(0.4)$ & $1(1.1)$ & $N S$ \\
Secondary endpoint & $78(22.7)$ & $46(18.3)$ & $32(34.8)$ & 0.002 \\
Hospitalization due to worsening of angina pectoris & $43(12.5)$ & $31(12.3)$ & $12(13.0)$ & $N S$ \\
Hospitalization due to worsening of heart failure & $30(8.7)$ & $15(6.0)$ & $15(16.3)$ & 0.005 \\
Acute MI & $2(0.6)$ & $0(0)$ & $2(2.2)$ & $N S$ \\
Sudden cardiac death & $3(0.9)$ & $0(0)$ & $3(3.3)$ & 0.019 \\
\hline
\end{tabular}

Data are no. (\%) of patients.

$\mathrm{OO}_{2} \mathrm{Hb}$, change of oxyhemoglobin $\left(\mathrm{O}_{2} \mathrm{Hb}\right)$ measured at the forehead from rest to peak exercise; NS, not significant; MI, myocardial infarction.

Table 2 Clinical Characteristics of the Subjects

\begin{tabular}{|c|c|c|c|c|}
\hline & $\begin{array}{c}\text { All patients } \\
(n=344)\end{array}$ & $\begin{array}{l}\text { Survivors } \\
(n=331)\end{array}$ & $\begin{array}{c}\text { Non-survivors } \\
(n=13)\end{array}$ & $p$ value \\
\hline Age (years) & $65.0 \pm 9.4$ & $64.8 \pm 9.3$ & $68.5 \pm 10.6$ & NS \\
\hline$M / F$, no. & $306 / 38$ & $294 / 37$ & $12 / 1$ & $N S$ \\
\hline \multicolumn{5}{|l|}{ Diagnosis } \\
\hline Old MI & $201(58.4)$ & $191(57.7)$ & $10(76.9)$ & NS \\
\hline Coronary artery disease without $M I$ & $143(41.6)$ & $140(42.3)$ & $3(23.1)$ & $N S$ \\
\hline \multicolumn{5}{|l|}{ Medication } \\
\hline Nitrates & $242(70.3)$ & $232(70.1)$ & $10(76.9)$ & NS \\
\hline Calcium-channel blockers & $194(56.4)$ & $192(58.0)$ & $2(15.4)$ & 0.003 \\
\hline$\beta$-blockers & $146(42.4)$ & $139(42.0)$ & $7(53.8)$ & $N S$ \\
\hline Angiotensin receptor blockers & $73(21.2)$ & $69(20.8)$ & $4(30.8)$ & $N S$ \\
\hline ACEIs & $61(17.7)$ & $59(17.8)$ & $2(15.4)$ & $N S$ \\
\hline Diuretics & $51(14.8)$ & $43(13.0)$ & $8(61.5)$ & $<0.0001$ \\
\hline Digitalis & $10(2.9)$ & $7(2.1)$ & $3(23.1)$ & 0.004 \\
\hline LVEF (\%) & $59.4 \pm 15.1$ & $60.6 \pm 14.0$ & $29.8 \pm 13.1$ & $<0.0001$ \\
\hline Heart rate at rest & $75.3 \pm 13.5$ & $75.1 \pm 13.4$ & $79.7 \pm 13.6$ & $N S$ \\
\hline SBP at rest & $124.9 \pm 19.2$ & $125.2 \pm 19.0$ & $117.8 \pm 23.0$ & NS \\
\hline Heart rate at peak exercise & $123.8 \pm 20.0$ & $124.3 \pm 20.0$ & $112.1 \pm 16.5$ & 0.03 \\
\hline SBP at peak exercise & $188.4 \pm 32.9$ & $190.0 \pm 32.1$ & $147.9 \pm 26.8$ & $<0.0001$ \\
\hline$\Delta \mathrm{O}_{2} \mathrm{Hb}(\mu \mathrm{mol} / \mathrm{L})$ & $1.6 \pm 3.3$ & $1.7 \pm 3.2$ & $-1.5 \pm 3.3$ & 0.0004 \\
\hline Peak $\dot{\mathrm{VO}} 2\left(\mathrm{ml} \cdot \mathrm{min}^{-1} \cdot \mathrm{kg}^{-1}\right)$ & $17.9 \pm 4.9$ & $18.1 \pm 4.9$ & $12.8 \pm 2.9$ & 0.0001 \\
\hline$\Delta \dot{V} O_{2} / \Delta W R\left(\mathrm{ml} \cdot \mathrm{min}^{-1} \cdot W^{-1}\right)$ & $9.3 \pm 2.1$ & $9.4 \pm 2.1$ & $6.8 \pm 1.5$ & $<0.0001$ \\
\hline$\dot{V} E / \dot{V} C O_{2}$ slope & $33.0 \pm 7.3$ & $32.6 \pm 7.0$ & $41.9 \pm 7.7$ & $<0.0001$ \\
\hline
\end{tabular}

Data are mean \pm SD or no. (\%) of patients unless otherwise indicated.

$A C E I$, angiotensin-converting enzyme inhibitor; $L V E F$, left ventricular ejection fraction; $S B P$, systolic blood pressure; $\dot{V} O_{2}$, peak

$\mathrm{O}_{2}$ uptake; $\triangle W R$, work rate; $\dot{V} E$, ventilation; $\dot{V} C_{2}$, increase in $\mathrm{CO}_{2}$ output. Other abbreviations see in Table 1.

heart failure, 2 had new acute myocardial infarction and 3 had a sudden cardiac death (only the first event was counted in this analysis). As compared to patients with a $\Delta \mathrm{O}_{2} \mathrm{Hb}$ of $\geq 0$, those with a $\Delta \mathrm{O}_{2} \mathrm{Hb}$ of $<0$ had higher rates of sudden cardiac death and hospitalization due to worsening of heart failure.

\section{Primary Endpoint}

Table 2 shows a comparison of clinical characteristics between survivors and non-survivors. There was no significant difference between the 2 groups regarding the presence of myocardial infarction, while the uses of calcium-channel blockers, diuretics and digitalis were different between the groups. The LVEF was $29.8 \pm 13.1 \%$ in non-survivors, which was lower than that of survivors $(60.6 \pm 14.0 \%, \mathrm{p}<0.0001)$. Both heart rate and systolic blood pressure at peak exercise were significantly lower in non-survivors than in survivors. The change of $\mathrm{O}_{2} \mathrm{Hb}$ at the forehead from rest to peak exercise $\left(\Delta \mathrm{O}_{2} \mathrm{Hb}\right)$ was significantly lower in non-survivors than in survivors $(-1.5 \pm 3.3$ vs $1.7 \pm 3.2 \mu \mathrm{mol} / \mathrm{L}, \mathrm{p}=0.0004)$. Nonsurvivors achieved lower peak $\dot{\mathrm{V}} \mathrm{O}_{2}$, lower $\Delta \dot{\mathrm{V}} \mathrm{O}_{2} / \Delta \mathrm{WR}$ and a higher $\dot{\mathrm{V} E} / \dot{\mathrm{V}} \mathrm{CO}_{2}$ slope than survivors.

Table 3 shows the univariate and multivariate Cox proportional hazards analyses of the association between the cardiopulmonary indexes including $\Delta \mathrm{O}_{2} \mathrm{Hb}$ and cardiac deaths. By the univariate analysis, LVEF, heart rate and systolic blood pressure at peak exercise, $\Delta \mathrm{O}_{2} \mathrm{Hb}$, peak $\dot{\mathrm{V}} 2$, $\Delta \dot{\mathrm{V}} \mathrm{O}_{2} / \Delta \mathrm{WR}$ and the $\dot{\mathrm{V}} / \dot{\mathrm{V}} \mathrm{O}_{2}$ slope were all found to be significant indexes for survival. When these significant indexes including use of medications were entered all together, only LVEF and $\triangle \mathrm{O}_{2} \mathrm{Hb}$ were found to be independent predictors for cardiac death. Fig 1 shows the Kaplan-Meier survival in each group of subjects divided on the basis of $\Delta \mathrm{O}_{2} \mathrm{Hb}$ at the forehead during exercise. The Kaplan-Meier survival curves demonstrated a significantly lower survival rate in patients with a $\Delta \mathrm{O}_{2} \mathrm{Hb}$ of $<0 \mu \mathrm{mol} / \mathrm{L}$ than in those with a $\Delta \mathrm{O}_{2} \mathrm{Hb}$ of $\geq 0 \mu \mathrm{mol} / \mathrm{L}(\mathrm{p}=0.0005)$. 
Table 3 Predictors for Cardiac Death

\begin{tabular}{|c|c|c|c|c|c|c|c|c|}
\hline & \multicolumn{4}{|c|}{ Univariate analysis } & \multicolumn{4}{|c|}{ Multivariate analysis } \\
\hline & $X_{2}$ & $p$ value & $H R$ & $95 \% C I$ & $X_{2}$ & $p$ value & $H R$ & $95 \% C I$ \\
\hline Age & 2.08 & 0.1491 & 1.050 & $0.983-1.122$ & - & - & - & - \\
\hline$L V E F$ & 29.73 & $<0.0001$ & 0.889 & $0.852-0.927$ & 11.18 & 0.0008 & 0.903 & $0.851-0.959$ \\
\hline Heart rate at peak exercise & 5.07 & 0.0243 & 0.969 & $0.943-0.996$ & 1.50 & 0.2210 & 0.968 & $0.919-1.020$ \\
\hline SBP at peak exercise & 19.70 & $<0.0001$ & 0.957 & $0.938-0.976$ & 0.95 & 0.3310 & 0.984 & $0.954-1.016$ \\
\hline $\mathrm{\Delta O}_{2} \mathrm{Hb}$ & 15.98 & $<0.0001$ & 0.793 & $0.707-0.888$ & 3.92 & 0.0476 & 0.793 & $0.631-0.998$ \\
\hline Peak $\dot{V} O_{2}$ & 16.57 & $<0.0001$ & 0.761 & $0.667-0.868$ & 0.01 & 0.9211 & 0.985 & $0.728-1.332$ \\
\hline$\Delta \dot{V} O_{2} / \Delta W R$ & 25.61 & $<0.0001$ & 0.615 & $0.509-0.742$ & 0.01 & 0.9379 & 0.976 & $0.533-1.787$ \\
\hline$\dot{V} E / \dot{V} C O_{2}$ slope & 22.20 & $<0.0001$ & 1.096 & $1.055-1.139$ & 1.75 & 0.1859 & 1.069 & $0.968-1.180$ \\
\hline Use of calcium-channel blockers & 6.99 & 0.0082 & 0.131 & $0.029-0.591$ & 1.88 & 0.1708 & 0.271 & $0.042-1.756$ \\
\hline Use of diuretics & 18.15 & $<0.0001$ & 11.509 & $3.739-35.424$ & 2.94 & 0.0865 & 0.154 & $0.018-1.307$ \\
\hline Use of digitalis & 12.82 & 0.0003 & 10.599 & $2.911-38.595$ & 1.31 & 0.2521 & 3.104 & $0.447-21.572$ \\
\hline
\end{tabular}

All variables were entered to a Cox proportional hazards model as continuous variables except for use of medications.

Age was not entered into the multivariate analysis because of no significance in the univariate analysis.

$H R$, hazard ratio; CI, confidence interval. Other abbreviations see in Tables 1,2.

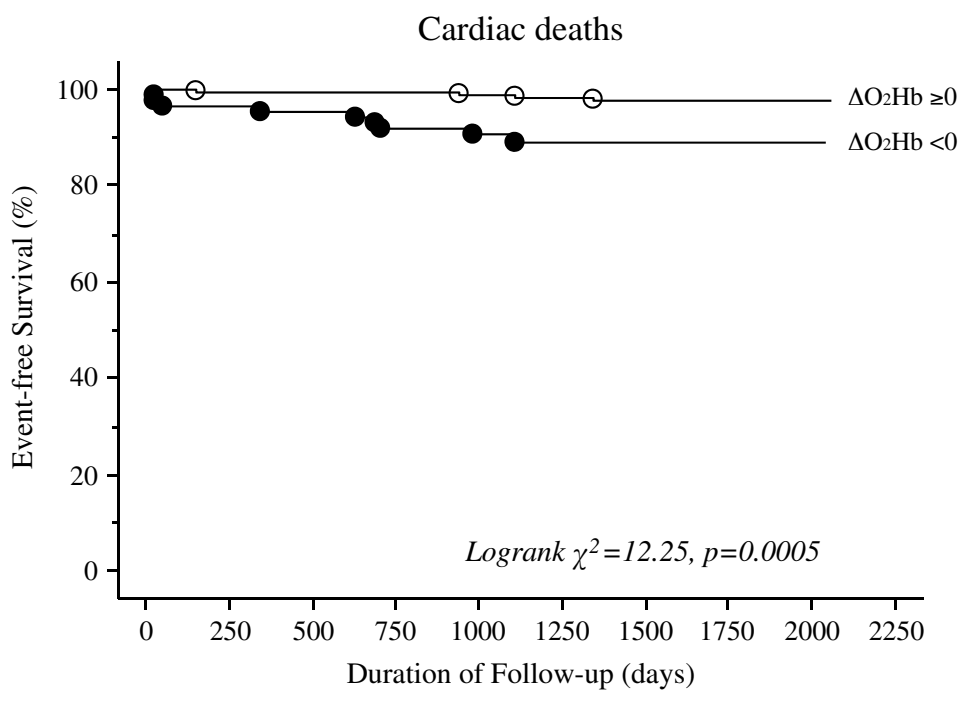

Fig 1. Kaplan-Meier survival curves for patients stratified into 2 groups on the basis of the change in oxyhemoglobin $\left(\mathrm{O}_{2} \mathrm{Hb}\right)$ during exercise $\left(\Delta \mathrm{O}_{2} \mathrm{Hb}\right)$ : patients with a $\Delta \mathrm{O}_{2} \mathrm{Hb}$ of $\geq 0 \mu \mathrm{mol} / \mathrm{L}(\mathrm{n}=252)$ and those with a $\Delta \mathrm{O}_{2} \mathrm{Hb}$ of $<0 \mu \mathrm{mol} / \mathrm{L}(\mathrm{n}=92)$. The survival rate in patients with a $\Delta \mathrm{O}_{2} \mathrm{Hb}$ of $<0 \mu \mathrm{mol} / \mathrm{L}$ was significantly lower than that in those with a $\Delta \mathrm{O}_{2} \mathrm{Hb}$ of $\geq 0 \mu \mathrm{mol} / \mathrm{L}(\mathrm{p}=0.0005)$.

Table 4 Clinical Characteristics of the Subjects

\begin{tabular}{|c|c|c|c|}
\hline & Event $(-)(n=266)$ & Event $(+)(n=78)$ & $p$ value \\
\hline Age (years) & $64.4 \pm 9.3$ & $66.8 \pm 9.5$ & $<0.05$ \\
\hline$M / F$, no. & $235 / 31$ & $71 / 7$ & $N S$ \\
\hline \multicolumn{4}{|l|}{ Diagnosis } \\
\hline Old MI & $148(55.6)$ & $53(67.9)$ & $N S$ \\
\hline Coronary artery disease without MI & $118(44.4)$ & $25(32.1)$ & $N S$ \\
\hline \multicolumn{4}{|l|}{ Medication } \\
\hline Nitrates & $184(69.2)$ & $58(74.4)$ & $N S$ \\
\hline Calcium-channel blockers & $158(59.4)$ & $36(46.2)$ & $N S$ \\
\hline$\beta$-blockers & $110(41.4)$ & $36(46.2)$ & $N S$ \\
\hline Angiotensin receptor blockers & $51(19.2)$ & $22(28.2)$ & $N S$ \\
\hline ACEIs & $46(17.3)$ & $15(19.2)$ & $N S$ \\
\hline Diuretics & $31(11.7)$ & $20(25.6)$ & 0.004 \\
\hline Digitalis & $3(1.1)$ & $7(9.0)$ & 0.002 \\
\hline $\operatorname{LVEF}(\%)$ & $61.5 \pm 13.2$ & $52.5 \pm 18.9$ & $<0.0001$ \\
\hline Heart rate at rest & $75.3 \pm 13.6$ & $75.3 \pm 13.0$ & $N S$ \\
\hline SBP at rest & $124.6 \pm 19.3$ & $125.8 \pm 18.8$ & $N S$ \\
\hline Heart rate at peak exercise & $125.4 \pm 20.2$ & $118.5 \pm 18.2$ & 0.007 \\
\hline SBP at peak exercise & $192.3 \pm 31.4$ & $175.3 \pm 34.5$ & $<0.0001$ \\
\hline$\Delta \mathrm{O}_{2} \mathrm{Hb}(\mu \mathrm{mol} / \mathrm{L})$ & $1.9 \pm 3.3$ & $0.5 \pm 2.9$ & 0.0009 \\
\hline Peak $\dot{\mathrm{V}} \mathrm{O}_{2}\left(\mathrm{ml} \cdot \mathrm{min}^{-1} \cdot \mathrm{kg}^{-1}\right)$ & $18.6 \pm 4.7$ & $15.4 \pm 4.6$ & $<0.0001$ \\
\hline$\Delta \dot{V} O_{2} / \Delta W R\left(\mathrm{ml} \cdot \mathrm{min}^{-1} \cdot \mathrm{W}^{-1}\right)$ & $9.6 \pm 2.1$ & $8.4 \pm 1.9$ & $<0.0001$ \\
\hline$\dot{V} E / \dot{V} C O_{2}$ slope & $32.3 \pm 6.9$ & $35.2 \pm 7.9$ & 0.002 \\
\hline
\end{tabular}

Data are mean \pm SD or no. (\%) of patients unless otherwise indicated. Abbreviations see in Tables 1,2. 
Table 5 Predictors for Cardiovascular Events

\begin{tabular}{|c|c|c|c|c|c|c|c|c|}
\hline & \multicolumn{4}{|c|}{ Univariate analysis } & \multicolumn{4}{|c|}{ Multivariate analysis } \\
\hline & $X_{2}$ & $p$ value & $H R$ & $95 \% C I$ & $X_{2}$ & p value & $H R$ & $95 \% C I$ \\
\hline Age & 4.72 & 0.0298 & 1.029 & $1.003-1.055$ & 0.22 & 0.6383 & 1.007 & $0.979-1.034$ \\
\hline LVEF & 33.16 & $<0.0001$ & 0.961 & $0.947-0.974$ & 8.87 & 0.0029 & 0.975 & $0.959-0.991$ \\
\hline Heart rate at peak exercise & 9.23 & 0.0024 & 0.983 & $0.972-0.994$ & 0.03 & 0.8692 & 1.001 & $0.987-1.015$ \\
\hline SBP at peak exercise & 23.18 & $<0.0001$ & 0.983 & $0.976-0.990$ & 1.10 & 0.2940 & 0.995 & $0.987-1.004$ \\
\hline $\mathrm{SO}_{2} \mathrm{Hb}$ & 14.00 & 0.0002 & 0.894 & $0.843-0.948$ & 3.93 & 0.0474 & 0.920 & $0.848-0.999$ \\
\hline Peak $\dot{V} \mathrm{O}_{2}$ & 34.75 & $<0.0001$ & 0.858 & $0.816-0.903$ & 3.90 & 0.0483 & 0.923 & $0.852-0.999$ \\
\hline$\Delta \dot{V} O_{2} / \Delta W R$ & 29.61 & $<0.0001$ & 0.765 & $0.695-0.842$ & 0.24 & 0.6268 & 0.960 & $0.813-1.133$ \\
\hline$\dot{V} E / \dot{V} C O_{2}$ slope & 17.70 & $<0.0001$ & 1.049 & $1.026-1.072$ & 0.02 & 0.8945 & 0.998 & $0.963-1.034$ \\
\hline Use of diuretics & 18.03 & $<0.0001$ & 3.055 & $1.824-5.116$ & 0.28 & 0.5942 & 0.822 & $0.399-1.692$ \\
\hline Use of digitalis & 12.47 & 0.0004 & 4.060 & $1.865-8.839$ & 1.16 & 0.2823 & 1.611 & $0.675-3.841$ \\
\hline
\end{tabular}

All variables were entered to a Cox proportional hazards model as continuous variables except for use of medications. Abbreviations see in Tables 1-3.

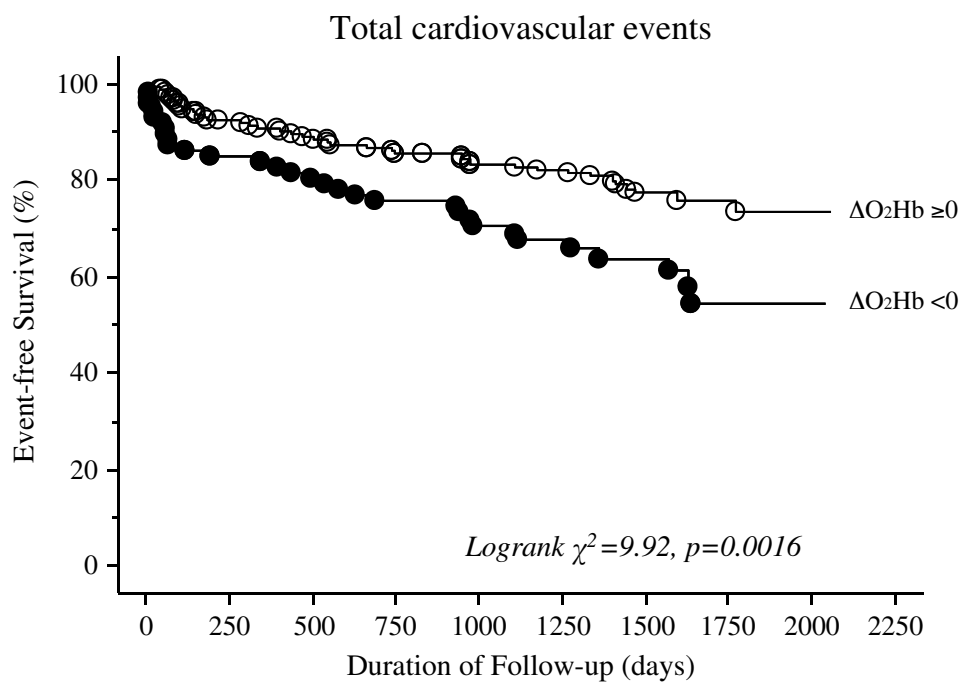

Fig 2. Kaplan-Meier event-free survival curves for patients stratified into 2 groups on the basis of the change in oxyhemoglobin $\left(\mathrm{O}_{2} \mathrm{Hb}\right)$ during exercise $\left(\Delta \mathrm{O}_{2} \mathrm{Hb}\right)$ : patients with a $\Delta \mathrm{O}_{2} \mathrm{Hb}$ of $\geq 0 \mu \mathrm{mol} / \mathrm{L}(\mathrm{n}=252)$ and those with a $\Delta \mathrm{O}_{2} \mathrm{Hb}$ of $<0 \mu \mathrm{mol} / \mathrm{L}(\mathrm{n}=92)$. The event-free survival rate in patients with a $\Delta \mathrm{O}_{2} \mathrm{Hb}$ of $<0 \mu \mathrm{mol} / \mathrm{L}$ was significantly lower than that in those with a $\Delta \mathrm{O}_{2} \mathrm{Hb}$ of $\geq 0 \mu \mathrm{mol} / \mathrm{L}(\mathrm{p}=$ 0.0016).
Secondary Endpoint

Table 4 shows a comparison of clinical characteristics between patients with cardiovascular events and those without events. There was no significant difference between the 2 groups regarding the presence of myocardial infarction. The mean age of the patients with cardiac events was $66.8 \pm 9.5$ years at the time of the exercise testing, which was significantly higher than that of the patients without events (64.4 9.3 years, $p<0.05)$. As compared to patients without cardiac events, those with events had significantly lower LVEF and lower heart rate and systolic blood pressure at peak exercise. The patients with events also had significantly lower $\Delta \mathrm{O}_{2} \mathrm{Hb}$ during exercise, lower peak $\dot{\mathrm{VO}}_{2}$, lower $\Delta \dot{\mathrm{V}} \mathrm{O}_{2} / \Delta \mathrm{WR}$, and a higher $\dot{\mathrm{V} E} / \dot{\mathrm{V}} \mathrm{CO} 2$ slope (Table 4$)$.

Table 5 shows univariate and multivariate Cox proportional hazards analyses of the association between cardiopulmonary indexes including $\Delta \mathrm{O}_{2} \mathrm{Hb}$ and cardiovascular events. In the univariate analysis, age, LVEF, both heart rate and systolic blood pressure at peak exercise, $\Delta \mathrm{O}_{2} \mathrm{Hb}$ at the forehead, peak $\dot{\mathrm{V}} \mathrm{O}_{2}, \Delta \dot{\mathrm{V}} \mathrm{O}_{2} / \Delta \mathrm{WR}$ and the $\dot{\mathrm{VE}} / \dot{\mathrm{V}} \mathrm{CO}_{2}$ slope were all found as significant prognostic indexes for event-free survival. In the multivariate analysis, only the LVEF, $\Delta \mathrm{O}_{2} \mathrm{Hb}$ at the forehead and peak $\mathrm{V}_{2}$ were found as independent prognostic indexes. As shown in Fig 2, the Kaplan-Meier survival curves demonstrate a significantly lower event-free survival rate in patients with a $\Delta \mathrm{O}_{2} \mathrm{Hb}$ of $<0 \mu \mathrm{mol} / \mathrm{L}$ than in those with a $\Delta \mathrm{O}_{2} \mathrm{Hb}$ of $\geq 0 \mu \mathrm{mol} / \mathrm{L}(\mathrm{p}=$
$0.0016)$

\section{Discussion}

During exercise, the sudden surge in $\mathrm{O}_{2}$ demand by muscle cells generates a tremendous increase in blood flow to the exercising muscle. The increased distribution of blood flow to the exercising muscle results in a relative hypoperfusion in other organs. As a consequence, cerebral circulation becomes insufficient during exercise, especially in cardiac patients whose cardiac output fails to increase normally. In our previous study, we found that cerebral oxygenation during exercise was strongly related to the indexes of CPX in cardiac patients? We also found that cerebral $\mathrm{O}_{2} \mathrm{Hb}$ actually decreased during exercise in a considerable number of patients with dilated cardiomyopathy, indicating the presence of their cerebral hypoperfusion. In the present study, we extended our scope, and newly discovered that the decrease in cerebral $\mathrm{O}_{2} \mathrm{Hb}$ during exercise predicts future cardiovascular events in patients with coronary artery disease.

\section{Mechanisms Determining Cerebral Oxygenation During Exercise}

Cerebral oxygenation is determined by $\mathrm{O}_{2}$ supply and $\mathrm{O}_{2}$ demand. Although not measured in the present study, cerebral blood flow is most important for $\mathrm{O}_{2}$ supply and is determined by perfusion pressure and cerebral vessel resistance. 
Cerebral perfusion pressure is equal to the difference between arterial pressure and venous (right atrial) pressure. While blood pressure maintenance is partly related to cardiac function, an attenuated increase in blood pressure during exercise impairs cerebral oxygenation irrespective of the presence of cardiac disease. In cardiac patients with left ventricular dysfunction, the level of venous pressure would be particularly increased during exercise, which might then decrease the level of cerebral perfusion pressure.

Even in the resting condition, patients with left ventricular dysfunction are known to have reduced cerebral blood flow as compared to normal subjects, which has been shown to be normalized by cardiac transplantation ${ }^{17}$ On the transition from rest to moderate exercise, global cerebral blood flow increases by $20-30 \%$ in both animals and humans ${ }^{18}$ During maximal exercise, however, a recent investigation by González-Alonso et al indicated that blood flow to the brain decreases even in healthy subjects! 18 They suggested the impaired increase in cardiac output, reduction in cerebral perfusion pressure, and local factors relating to the vasoconstrictor and/or vasodilator activities in the brain as possible mechanisms underlying this phenomenon 18 Thus, cerebral blood flow during maximal exercise would be more easily decreased in cardiac patients, such as those with coronary artery disease, because of their insufficient increase in cardiac output during exercise. Although not measured in the present study, another possible determinant of cerebral oxygenation is the level of $\mathrm{PaCO}_{2}$ during exercise. Cerebral blood flow is known to positively correlate with $\mathrm{PaCO}_{2}$; a decrease in $\mathrm{PaCO}_{2}$ leads to cerebral hypoperfusion and a rise in $\mathrm{PaCO}_{2}$ increases cerebral blood flow.

\section{Study Limitations}

From the results of the previous investigations, $1,2,7,19$ we assumed that the decrease in $\mathrm{O}_{2} \mathrm{Hb}$ during exercise would be an abnormal phenomenon. Thus, we used the $\Delta \mathrm{O}_{2} \mathrm{Hb}$ level of " 0 " as a cut-off point for the Kaplan-Meier method without using a receiver operating characteristics (ROC) curve analysis.

The possibility of contamination from extracranial tissues has to be considered when we evaluate cerebral oxygenation using NIRS attached to the forehead. In our previous investigations performed with the same methodology, pulse oximetric saturation was also measured at the earlobe near the NIRS probes during exercise!,2 There was no decrease in pulse oximetric saturation during exercise in spite of the apparent decrease in $\mathrm{O}_{2} \mathrm{Hb}$ at the forehead. Thus, we assume that the influence of extracranial factors was minimal for the present findings. Our previous report has already confirmed the good reproducibility of cerebral $\mathrm{O}_{2} \mathrm{Hb}$ measurements during exercise by this technique?

In the present study, we selected only the patients with coronary artery disease. However, the prognostic value of decreased cerebral $\mathrm{O}_{2} \mathrm{Hb}$ during exercise would be applicable to patients with any type of left ventricular dysfunction if the cardiac output response to exercise is impaired. Although patients with cerebrovascular disease having a clinical manifestation were excluded in the present study, the decrease in cerebral $\mathrm{O}_{2} \mathrm{Hb}$ during exercise in patients with a poor prognosis might have partly stemmed from concomitant stenosis in small cerebral arteries?

\section{Clinical Implications}

Quite recently, we compared the decreased level of cerebral $\mathrm{O}_{2} \mathrm{Hb}$ during exercise in cardiac patients with those in subjects who had experienced reduced consciousness due to a sudden drop in blood pressure induced by a parasympathetic reflex or sustained ventricular tachycardia 19 We found that the decreases in cerebral $\mathrm{O}_{2} \mathrm{Hb}$ during exercise in some patients were comparable to those in subjects who experienced reduced consciousness. This finding suggests that the index of cerebral oxygenation might drop to levels low enough during maximal exercise to affect the level of consciousness in some cardiac patients, especially those with severe left ventricular dysfunction. 19

While factors determining cerebral oxygenation are complex, the regulation of cerebral oxygenation is critically important in humans even during exercise. This regulation must depend largely on cardiac function and additionally on the cerebral vessel resistance. Both of these factors would be diseased in patients with coronary artery disease, as it is one of the manifestations resulting from systemic arteriosclerosis. The decrease in cerebral $\mathrm{O}_{2} \mathrm{Hb}$ during exercise in our patients must reflect the disturbance of auto regulation of cerebral oxygenation. In the present study, the patients with a $\Delta \mathrm{O}_{2} \mathrm{Hb}$ of $<0$ had significantly higher rates of sudden cardiac death and hospitalization due to worsening of heart failure, as compared to those with a $\Delta \mathrm{O}_{2} \mathrm{Hb}$ of $\geq 0$. However, there was no significant difference in the event rate of hospitalization due to worsening of angina pectoris or of acute myocardial infarction between the 2 groups. Our findings suggest that the patients with the disturbance of cerebral oxygenation, which is related to the underlying coronary artery disease, were prone to have future cardiovascular events, especially worsening of heart failure.

Cerebral $\mathrm{O}_{2} \mathrm{Hb}$ during exercise reflects cerebral oxygenation, which is determined by cardiac function and cerebral vessel resistance. The decrease in cerebral $\mathrm{O}_{2} \mathrm{Hb}$ in cardiac patients would imply impaired cardiac response to exercise, that is, the insufficient heart's pumping reserve. The heart's pumping reserve during exercise does not necessarily correlate with resting cardiac function. By these reasons, $\Delta \mathrm{O}_{2} \mathrm{Hb}$ during exercise in our subjects predicted the future events related to heart failure independently from resting LVEF.

Patients with decreased cerebral $\mathrm{O}_{2} \mathrm{Hb}$ during exercise would be exposed to a chronic impairment of cerebral oxygenation during daily life, which might lead to cognitive dysfunction and decreases in quality of life and activities of daily living. In the future, a consideration of the specific treatments that might improve cerebral oxygenation might become important in patients with decreased cerebral $\mathrm{O}_{2} \mathrm{Hb}$ during exercise. In patients with severely decreased LVEF, such as the candidates for cardiac transplantation, the parameters obtained from CPX are known to be superior to resting cardiac function for predicting future prognosis? In the present study, however, resting LVEF was confirmed to be a strong prognostic index in patients with coronary artery disease with a wide range of LVEF.

\section{Conclusions}

The decrease in cerebral $\mathrm{O}_{2} \mathrm{Hb}$ during exercise was found to strongly predict future cardiovascular events in patients with coronary artery disease. The prognostic power of cerebral $\mathrm{O}_{2} \mathrm{Hb}$ during exercise for future cardiovascular events was independent of the indexes obtained from CPX, and even stronger than these indexes for cardiac mortality. 


\section{References}

1. Koike A, Hoshimoto M, Nagayama O, Tajima A, Kubozono T, Oikawa K, et al. Cerebral oxygenation during exercise and exercise recovery in patients with idiopathic dilated cardiomyopathy. Am J Cardiol 2004; 94: 821-824.

2. Koike A, Itoh H, Oohara R, Hoshimoto M, Tajima A, Aizawa T, et al. Cerebral oxygenation during exercise in cardiac patients. Chest 2004; 125: $182-190$.

3. Mancini DM, Eisen H, Kussmaul W, Mull R, Edmunds LH, Wilson JR. Value of peak exercise oxygen consumption for optimal timing of cardiac transplantation in ambulatory patients with heart failure. Circulation 1991; 83: 778-786.

4. Koike A, Itoh H, Kato M, Sawada H, Aizawa T, Fu LT, et al. Prognostic power of ventilatory responses during submaximal exercise in patients with chronic heart disease. Chest 2002; 121: 1581-1588.

5. Lee CW, Lee JH, Kim JJ, Park SW, Hong MK, Kim ST, et al. Cerebral metabolic abnormalities in congestive heart failure detected by proton magnetic resonance spectroscopy. J Am Coll Cardiol 1999; 33: $1196-1202$.

6. Lee CW, Lee JH, Lim TH, Yang HS, Hong MK, Song JK, et al. Prognostic significance of cerebral metabolic abnormalities in patients with congestive heart failure. Circulation 2001; 103: 2784-2787.

7. Nagayama O, Koike A, Hoshimoto M, Yamaguchi K, Tajima A, Goda A, et al. Influence of cerebrovascular arteriosclerosis on cerebral oxygenation during exercise. Circ J 2007; 71: 782-787.

8. Tunstall-Pedoe H, Kuulasmaa K, Amouyel P, Arveiler D, Rajakangas AM, Pajak A. Myocardial infarction and coronary deaths in the World Health Organization MONICA Project. Circulation 1994; 90: $583-612$.

9. Torp-Pedersen C, Køber L, Elming H, Burchart H. Classification of sudden and arrhythmic death. Pacing Clin Electrophysiol 1997; 20: $2545-2552$

10. Koike A, Hiroe M, Adachi H, Yajima T, Yamauchi Y, Nogami A, et al. Oxygen uptake kinetics are determined by cardiac function at onset of exercise rather than peak exercise in patients with prior myocardial infarction. Circulation 1994; 90: 2324-2332.

11. Nollert G, Möhnle P, Tassani-Prell P, Reichart B. Determinants of cerebral oxygenation during cardiac surgery. Circulation 1995; 92(Suppl): II-327-II-333.

12. Villringer K, Minoshima S, Hock C, Obrig H, Ziegler S, Dirnagl U, et al. Assessment of local brain activation: A simultaneous PET and near-infrared spectroscopy study. Adv Exp Med Biol 1997; 413: 149-153.

13. Suzuki S, Takasaki S, Ozaki T, Kobayashi Y. A tissue oxygenation monitor using NIR spatially resolved spectroscopy. Proc SPIE 1999; 3597: $582-592$.

14. Quaresima V, Sacco S, Totaro R, Ferrari M. Noninvasive measurement of cerebral hemoglobin oxygen saturation using two near infrared spectroscopy approaches. J Biomed Opt 2000; 5: 201-205.

15. Al-Rawi PG, Smielewski P, Kirkpatrick PJ. Evaluation of a nearinfrared spectrometer (NIRO 300) for the detection of intracranial oxygenation changes in the adult head. Stroke 2001; 32: 2492-2500.

16. van der Zee P, Cope M, Arridge SR, Essenpreis M, Potter LA, Edwards AD, et al. Experimentally measured optical pathlengths for the adult head, calf and forearm and the head of the newborn infant as a function of inter optode spacing. Adv Exp Med Biol 1992; 316: $143-153$.

17. Choi BR, Kim JS, Yang YJ, Park KM, Lee CW, Kim YH, et al. Factors associated with decreased cerebral blood flow in congestive heart failure secondary to idiopathic dilated cardiomyopathy. Am J Cardiol 2006; 97: 1365-1369.

18. González-Alonso J, Dalsgaard MK, Osada T, Volianitis S, Dawson EA, Yoshiga CC, et al. Brain and central haemodynamics and oxygenation during maximal exercise in humans. J Physiol 2004; 557: $331-342$.

19. Koike A, Hoshimoto M, Tajima A, Nagayama O, Yamaguchi K, Goda $\mathrm{A}$, et al. Critical level of cerebral oxygenation during exercise in patients with left ventricular dysfunction. Circ J 2006; 70: 1457-1461. 